\title{
INTERNALISASI NILAI-NILAI KEJUANGAN JENDERAL SOEDIRMAN DALAM PENDIDIKAN KARAKTER DI SMA TARUNA NUSANTARA
}

\author{
Mokhammad Unggul Wibowo, Djoko Suryo, Dwi Siswoyo \\ SMA Negeri 3 Cilacap, Universitas Gadjah Mada, Universitas Negeri Yogyakarta \\ munggulwibowo@yahoo.co.id,djoko98@yahoo.com,dwi_siswoyo@uny.ac.id
}

\begin{abstract}
Abstrak
Penelitian ini bertujuan untuk mendeskripsikan: (1) nilai-nilai kejuangan Jenderal Soedirman yang diinternalisasi; (2) proses internalisasi nilai-nilai kejuangan Jenderal Soedirman; dan (3) efektivitas internalisasi nilai-nilai kejuangan Jenderal Soedirman di SMA Taruna Nusantara. Penelitian ini adalah deskriptif kualitatif dengan pendekatan fenomenologi. Pengumpulan data menggunakan wawancara, observasi, dan studi dokumentasi. Analisis data menggunakan model analisis data kualitatif Miles \& Huberman. Hasil penelitian menunjukkan bahwa nilai-nilai kejuangan Jenderal Soedirman yang diinternalisasi di SMA Taruna Nusantara belum dirumuskan secara eksplisit. Internalisasi nilai-nilai kejuangan Jenderal Soedirman dilaksanakan pada tahapan pertama pendidikan karakter, menggunakan pendekatan inspiratif dan pola tindak pengajaran, pengasuhan, dan pelatihan. Internalisasi nilai-nilai kejuangan Jenderal Soedirman di SMA Taruna Nusantara telah memberikan pengetahuan moral (moral knowing) kepada para siswa. Nilai-nilai tersebut diinternalisasi oleh para siswa sehingga mereka memiliki perasaan moral (moral feeling). Dalam menghadapi permasalahan hidup, mereka mengaktualisasikan nilai-nilai kejuangan Jenderal Soedirman tersebut sebagai perilaku moral (moral action).
\end{abstract}

Kata kunci: nilai kejuangan, internalisasi nilai, dan pendidikan karakter

\section{THE GENERAL SUDIRMAN STRUGGLE VALUES INTERNALIZATION IN CHARACTER EDUCATION IN TARUNA NUSANTARA SENIOR HIGH SCHOOL}

Mokhammad Unggul Wibowo, Djoko Suryo, Dwi Siswoyo

SMA Negeri 3 Cilacap, Universitas Gadjah Mada, Universitas Negeri Yogyakarta munggulwibowo@yahoo.co.id,djoko98@yahoo.com,dwi_siswoyo@uny.ac.id

\begin{abstract}
This study aims to describe: (1) the General Sudirman struggle values which are internalized; (2) the process of the General Sudirman struggle value internalization; and (3) the effectiveness of the General Sudirman struggle values internalization in Taruna Nusantara Senior High School. This study is a qualitative descriptive by using phenomenology approach. Data collection using interviews, observation, and documentation studies. The data analysis used Miles \& Huberman qualitative data analysis model. The study findings are the General Sudirman struggle values which are internalized in Taruna Nusantara Senior High School have not explicitly formulated. The General Sudirman struggle values internalization done in the first step of character education, using inspirative and teaching pattern approach, parenting, and training. The General Sudirman struggle values internalization in Taruna Nusantara Senior High School Magelang has effectively given moral knowing. Those values then internalized by the students so that they have moral feeling. In facing life problem, they actualize the General Sudirman Struggle Values as moral action.
\end{abstract}

Keywords: struggle values, value internalization, character education 


\section{PENDAHULUAN}

Degradasi moral dan etika berperila$\mathrm{ku}$ yang melanda bangsa Indonesia pada akhir-akhir ini, telah menjadi krisis yang nyata dan mengkhawatirkan. Krisis itu antara lain diakibatkan meningkatnya pergaulan seks bebas, perkosaan, sodomi, pornografi melalui media sosial dan internet, maraknya kekerasan (bullying) anak-anak dan remaja di lingkungan sekolah maupun masyarakat, kejahatan terhadap teman, tawuran, pencurian, kebiasaan menyontek di kalangan pelajar, penyalahgunaan obat-obatan, perusakan milik orang lain, dan lain-lain (Zubaedi, 2011, pp. $1-2)$.

Krisis moral ini mengindikasikan bahwa pendidikan agama dan moral yang diberikan di sekolah selama ini belum memberikan dampak yang signifikan terhadap perilaku manusia Indonesia. Proses pewarisan dan pengembangan nilai-nilai budaya bangsa dalam pendidikan selama ini masih terlalu dangkal. Pelaksanaan pendidikan karakter, terutama pada Pendidikan Agama dan Pendidikan Kewarganegaraan $(\mathrm{PKn})$, masih cenderung bersifat transfer pengetahuan. Pembelajaran baru menyentuh taraf permukaan, belum menekankan pada proses bagaimana nilai-nilai dapat diinternalisasi pada diri peserta didik.

Menurut Sastrapratedja (1993, p. 20), nilai merupakan realitas abstrak. Nilai dirasakan dalam diri kita sebagai daya dorong atau prinsip-prinsip yang menjadi pedoman hidup. Karena itu, nilai menduduki tempat penting dalam kehidupan seseorang. Nilai merupakan sesuatu yang diyakini kebenarannya dan dianut serta dijadikan sebagai acuan dasar individu dan masyarakat dalam menentukan sesuatu yang dipandang baik, benar, bernilai maupun berharga. Nilai merupakan bagian dari kepribadian individu yang berpengaruh terhadap pemilihan cara maupun tujuan tindakan dari beberapa alternatif serta mengarahkan kepada tingkah laku dalam kehidupan seharihari. Oleh karena itu, nilai dalam setiap individu dapat mewarnai kepribadian kelompok atau kepribadian bangsa.

Lickona (1991, pp. 81-82) memberikan suatu cara berpikir tentang karakter yang tepat bagi pendidikan nilai yaitu karakter terdiri dari nilai operatif, nilai dalam tindakan. Kita berproses dalam karakter kita, sering suatu nilai menjadi suatu kebaikan, suatu dispo- sisi batin yang dapat diandalkan untuk menanggapi situasi dengan cara yang menurut moral itu baik. Karakter yang demikian memiliki tiga bagian yang saling berhubungan, yakni pengetahuan moral (moral knowing), perasaan moral (moral feeling), dan perilaku moral (moral action). Karakter yang baik terdiri dari mengetahui hal yang baik, menginginkan hal yang baik, dan melakukan hal yang baik. Untuk itu nilai-nilai yang baik perlu diinternalisasi ke dalam diri peserta didik.

Menurut Kamus Besar Bahasa Indonesia (Pusat Bahasa Depdiknas, 2002, p. 439) internalisasi merupakan penghayatan terhadap suatu nilai sehingga menjadi keyakinan, kemudian dengan kesadaran menerima kebenaran nilai tersebut, dan selanjutnya diwujudkan dalam sikap dan perilaku. Menurut Meissner (Walls \& Poulton, 2001, p. 6):

Internalization, then, is any process of transformation by which external relationship, object representations, and forms of regulation become part of the inner psychic structure and thus part of the 'inner world'.

Meisner memaknai internalisasi adalah setiap proses transformasi di mana hubungan eksternal, representasi objek, dan bentuk peraturan menjadi bagian dalam dari struktur psikisnya dan dengan demikian menjadi bagian dari 'dunia batin'.

Proses internalisasi nilai, menurut Muhaimin (1996, p. 153), dibagi menjadi tiga tahap, yaitu tahap transformasi nilai, tahap transaksi nilai, dan tahap transinternalisasi. Tahap Transformasi Nilai, merupakan suatu proses yang dilakukan oleh pendidik dalam menginformasikan nilai-nilai yang baik dan kurang baik. Pada tahap ini hanya terjadi komunikasi verbal antara pendidik dengan peserta didik. Tahap Transaksi Nilai, merupakan tahap pendidikan nilai dengan jalan melakukan komunikasi dua arah, atau interaksi antara peserta didik dengan pendidik yang bersifat interaksi timbal-balik. Tahap Transinternalisasi, merupakan tahap yang jauh lebih mendalam dari tahap transaksi. Pada tahap ini bukan hanya dilakukan dengan komunikasi verbal tapi juga sikap mental dan kepribadian. Jadi pada tahap ini komunikasi kepribadian yang berperan secara aktif.

Internalisasi nilai-nilai tidak bisa berlangsung secara optimal tanpa adanya faktor 
pembiasaan (habituasi) dan faktor keteladanan. Pembentukan karakter merupakan sebuah proses, harus dilatih atau dibiasakan secara terus-menerus, serius, dan proporsional. Melalui pembiasaan tersebut diharapkan nilai-nilai positif dapat diinternalisasi secara optimal dan permanen, sehngga akan terbentuk karakter positif pada diri peserta didik (Wibowo, 2012, p. 22).

Selain pembiasaan, keteladanan menjadi faktor penting dalam pendidikan karakter. Menurut Scerenko (1997, p. 16) pendidikan karakter dapat dimaknai sebagai upaya yang sungguh-sungguh dengan cara mana ciri kepribadian positif dikembangkan, didorong, dan diberdayakan melalui keteladanan, kajian (sejarah, dan biografi para bijak dan pemikir besar), serta praktik emulasi (usaha yang maksimal untuk mewujudkan hikmah dari apa-apa yang diamati dan dipelajari).

Keteladanan merupakan suatu model pendidikan dengan cara memberi contoh yang baik (role model) kepada peserta didik, baik dalam ucapan ataupun perbuatan. Bapak Pendidikan Nasional, Ki Hajar Dewantara, melalui Perguruan Taman Siswa telah menekankan pentingnya keteladanan. Salah satu semboyan Taman Siswa adalah ing ngarsa sung tulada, yang bermakna bahwa seorang pendidik hendaknya memberikan teladan yang baik kepada anak didiknya.

Salah satu krisis yang dihadapi bangsa Indonesia saat ini adalah krisis keteladanan. Kehidupan yang mengarah kepada serba material oriented dan era informasi yang mengaburkan batas-batas negara dan budaya, telah mengakibatkan terjadinya penurunan semangat kebangsaan dan karakter kepribadian bangsa. Solusi alternatif untuk mereduksi permasalahan tersebut adalah membangun karakter bangsa dengan menghadirkan keteladanan dari sosok-sosok tokoh nasional sebagai wujud nyata adanya kepribadian dan nilai-nilai positif yang dapat dijadikan sebagai contoh dan panutan seluruh bangsa Indonesia. Keteladanan dari tokoh-tokoh nasional Indonesia perlu digali untuk dapat dijadikan sebagai sumber nilai-nilai dalam pembentukan karakter siswa di sekolah, sehingga akan terbentuk ketahanan pribadi yang mengarah kepada pembentukan ketahanan nasional.

Nilai kejuangan para generasi sebelum kita perlu diwariskan agar proses perkembangan dan pembangunan bangsa ini ber- langsung terus menerus dan tidak memudar (Purwoko, 2001, p. 1). Dikaitkan dengan nasionalisme, kejuangan adalah semangat pengabdian yang ikhlas diwujudkan dalam perilaku hidup yang pantang menyerah, tahan menderita dan senantiasa mengutamakan kepentingan negara dan bangsa. Dengan demikian, nilai kejuangan dapat didefinisikan sebagai konsep yang berkenaan dengan sifat, mutu, keadaan yang berguna bagi manusia dan kemanusiaan yang menyangkut perihal perang, kelahi, lawan, dan laga. Kata nilai kejuangan dikenakan terhadap konsepsi abstrak, anutan, faham dan pendorong yang menyebabkan orang dapat berperang, berkelahi, berlawan dan berlaga, sehingga bermanfaat bagi dirinya untuk menang (Suhady \& Sinaga, 2006, p. 5).

Menurut Madjid (2001, p. 1), kejuangan mengandung makna kesadaran tentang adanya makna dan tujuan hidup yang lebih tinggi daripada kepentingan pribadi atau kelompok dalam arti sempit, disusul dengan kesediaan untuk berkorban guna mewujudkan makna dan tujuan hidup itu. Karena itu, nilai kejuangan dengan sendirinya berkaitan dengan makna dan tujuan hidup tersebut yang bersifat tidak terbatas hanya kepada kehidupan terestrial (duniawi), tetapi selestial atau transendental (ukhrawi).

Pendidikan karakter penting sekali melakukan internalisasi nilai-nilai kejuangan dari tokoh-tokoh nasional Indonesia, dan disinkronisasi dengan internalisasi nilai-nilai etika inti seperti kepedulian, kejujuran, keadilan, tanggung jawab, dan rasa hormat terhadap diri dan orang lain bersama dengan nilai-nilai kinerja pendukungnya seperti ketekunan, etos kerja yang tinggi, dan kegigihan sebagai basis karakter yang baik. Sekolah harus berkomitmen untuk mengembangkan karakter peserta didik berdasarkan nilai-nilai dimaksud, mendefinisikannya dalam bentuk perilaku yang dapat diamati dalam kehidupan sekolah sehari-hari, mencontohkan nilai-nilai itu, mengkaji dan mendiskusikannya, menggunakannya sebagai dasar dalam hubungan antarmanusia, dan mengapresiasi manifestasi nilai-nilai tersebut di sekolah dan masyarakat. Semua komponen sekolah harus bertanggung jawab terhadap standar-standar perilaku yang konsisten sesuai dengan nilai-nilai inti.

Sejak diberlakukannya sistem manajemen berbasis sekolah (school based management) pada tahun 2004, mestinya setiap 
sekolah memiliki keleluasaan untuk mengembangkan pengelolaan sekolah sesuai dengan kebutuhan masing-masing, termasuk di dalamnya pengembangan kultur sekolah (school culture) dan pendidikan karakter. Namun hingga saat ini baru sedikit sekolah di Indonesia yang berhasil mengembangkan kultur sekolah dan pendidikan karakter. Belum setiap sekolah berhasil mengimplementasikan pendidikan karakter secara efektif, merumuskan cara pendisiplinan dan pembiasaan karakter yang akan dibentuk, dan membentuk school culture. Sebagian besar sekolah di Indonesia masih terpengaruh pola lama yaitu menunggu kebijakan dan petunjuk yang berasal dari atas. Dari sedikit sekolah yang dimaksud, antara lain adalah SMA Taruna Nusantara.

Penelitian ini berusaha mengungkap secara mendalam proses internalisasi nilainilai kejuangan Jenderal Soedirman dalam pendidikan karakter di SMA Taruna Nusantara, berusaha menemukan teori pembentukan karakter, dan berusaha mengkritisi fenomenafenomena yang ada dengan berbagai teori yang ada. Pemilihan nilai-nilai kejuangan Jenderal Soedirman sebagai muatan materi pendidikan karakter hanyalah salah satu alternatif dari sekian tokoh nasional yang dapat dipilih. Semakin banyak digali keteladanan dari tokoh-tokoh nasional akan semakin mendekatkan wujud nyata dari karakter bangsa yang diharapkan.

\section{METODE PENELITIAN}

Penelitian ini merupakan jenis penelitian kualitatif dengan pendekatan fenomenologi, yaitu penelititan yang bermaksud untuk memahami fenomena tentang apa yang dialami oleh subjek penelitian misalnya perilaku, persepsi, motivasi, tindakan, dan lainlain. Polkinghorne (Creswell, 2007, p. 51) mengemukakan bahwa: a phenomenological study describe the meaning of the lived experiences for several indivuals about a concept or the phenomenon. Fenomena-fenomena sosial yang terjadi di SMA Taruna Nusantara terkait dengan nilai-nilai kejuangan Jenderal Soedirman yang diinternalisasi, proses internalisasi nilai-nilai kejuangan Jenderal Soedirman dalam pendidikan karakter, dan efektivitas internalisasi nilai-nilai kejuangan Jenderal Soedirman, dideskripsikan dalam bentuk kata-kata, kalimat, dan gambar, berdasarkan hasil pengamatan, studi dokumentasi, dan wawancara dengan subjek penelitian.

Penelitian ini dilaksanakan di SMA Taruna Nusantara yang terletak di Kabupaten Magelang. Pemilihan SMA Taruna Nusantara sebagai lokasi penelitian karena SMA ini memiliki beberapa keunikan. SMA Taruna Nusantara memiliki visi membentuk kader pemimpin bangsa berkualitas dan berkarakter yang berwawasan kebangsaan, kejuangan, kebudayaan, dengan bercirikan kenusantaraan serta memiliki daya saing nasional maupun internasional (LPTTN, 1989, p. 5).

Untuk pembentukan karakter siswa agar sesuai dengan visi, misi, dan tujuan sekolah, SMA Taruna Nusantara menggunakan kurikulum khusus pendidikan karakter yang disusun sendiri, di samping kurikulum nasional yang berlaku. SMA Taruna Nusantara juga memiliki kultur sekolah (school culture) tersendiri. Sebagai sekolah yang memiliki keterkaitan erat dengan TNI, pembentukan kultur SMA Taruna Nusantara tidak bisa dilepaskan dari keteladanan sosok Bapak TNI yaitu Jenderal Soedirman. Nilai-nilai kejuangan Jenderal Soedirman dijadikan muatan materi pendidikan karakter dan diinternalisasi ke dalam diri setiap siswa di SMA Taruna Nusantara.

Subjek penelitian adalah kepala sekolah, wakil kepala sekolah, staf ahli bidang penjaminan mutu, pamong, siswa, alumni, dan orang tua siswa. Pengumpulan data dengan menggunakan teknik observasi partisipatif, wawancara mendalam, dan studi dokumentasi. Penentuan responden dipilih secara purposive, yaitu dipilih dengan pertimbangan dan tujuan tertentu. Peneliti memilih orang tertentu yang dipertimbangkan akan memberikan data yang diperlukan (purposive); selanjutnya berdasarkan data atau informasi yang diperoleh dari responden sebelumnya itu, peneliti dapat menetapkan responden lainnya yang dipertimbangkan akan memberikan data lebih lengkap.

Analisis data dalam penelitian kualitatif ini menggunakan model analisis data Miles \& Huberman (1992, p. 2). Ada empat tahap penting analisis yang saling berkaitan, yaitu: pengumpulan data, reduksi data, penyajian data, dan penarikan kesimpulan atau verifikasi.

Berdasarkan konsep Miles \& Huberman seperti yang tertera pada Gambar 1, analisis data dilakukan setelah data terkumpul 
seluruhnya. Adapun uraian masing-masing komponen adalah sebagai berikut.

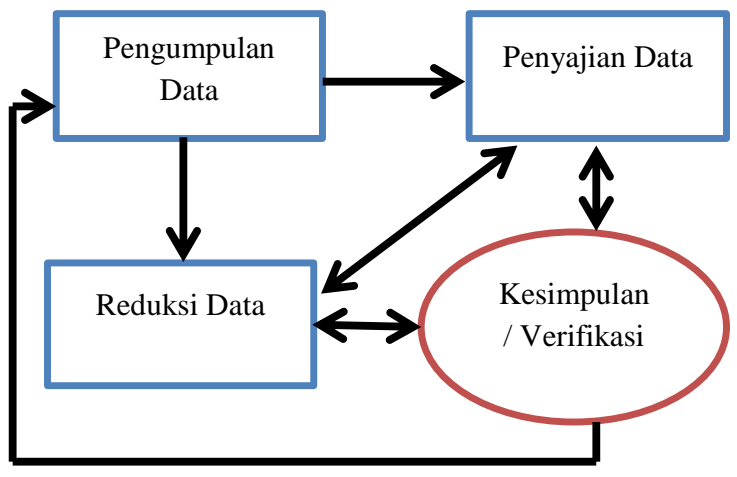

Gambar 1. Model Analisis Data

Kualitatif (Miles \& Huberman, 1992)

Pengumpulan data, yaitu proses pengumpulan data yang diperoleh secara keseluruhan di lapangan. Data tersebut terdiri dari beraneka ragam data, termasuk data mentah di dalamnya tentang pelaksanaan pendidikan karakter melalui role model, proses internalisasi nilai-nilai kejuangan Jenderal Soedirman dengan pendekatan inspiratif, pengembangan kultur sekolah.

Reduksi data, yaitu sebagai proses pemilihan, pemusatan perhatian pada penyederhanaan dan transformasi data mentah yang muncul dari catatan-catatan tertulis di lokasi penelitian. Proses reduksi ini dilakukan sejak pengumpulan data dimulai dengan membuat ringkasan, memberikan kode, menelusur tema, membuat gugus-gugus, menulis memo dan lain sebagainya dengan maksud menyisihkan data atau informasi yang tidak relevan dengan tema penelitian ini. Reduksi data ini bertujuan untuk menajamkan, menggolongkan, dan mengarahkan data yang berguna menghasilkan data yang potensial untuk menjawab pertanyaan-pertanyaan penelitian mengenai internalisasi nilai-nilai kejuangan Jenderal Soedirman dalam pendidikan karakter di SMA Taruna Nusantara.

Penyajian data, yaitu pendeskripsian sekumpulan informasi tersusun yang memberikan kemungkinan adanya penarikan kesimpulan dan pengambilan tindakan dari data mengenai nilai-nilai kejuangan Jenderal Soedirman, proses internalisasi nilai-nilai kejuangan Jenderal Soedirman, dan efektivitas internalisasi nilai-nilai kejuangan Jenderal Soedirman. Penyajian data kualitatif disajikan dalam bentuk naratif, dan juga bisa berbentuk bagan, tabel, diagram, dan matrik. Seluruh data dirancang sedemikian rupa sehingga membentuk informasi yang rapi, komprehensif, dan mudah dipahami oleh pembaca.

Pembuatan kesimpulan, yaitu kegiatan akhir dari analisis data yang berupa kegiatan interpretasi atau pemaknaan dari hasil penelitian. Dalam membuat simpulan digunakan beberapa cara seperti menggunakan pengklasteran atau pengelompokan, menemukan pola dan tema mengenai nilai-nilai kejuangan Jenderal Soedirman, proses internalisasi nilainilai kejuangan Jenderal Soedirman, dan efektivitas internalisasi nilai-nilai kejuangan Jenderal Soedirman. Selanjutnya peneliti menguji kebenaran, kecocokan, dan kekokohan data yang terkumpul yaitu mengenai internalisasi nilai-nilai kejuangan Jenderal Soedirman dalam pendidikan karakter di SMA Taruna Nusantara, dengan kondisi riil di lapangan.

\section{HASIL PENELITIAN DAN PEMBAHASAN}

\section{Nilai-nilai Kejuangan Jenderal Soedirman yang Diinternalisasi}

Dalam Buku Kurikulum Khusus SMA Taruna Nusantara (YKPP-LPTTN, 2013, pp. 10-11) disebutkan bahwa aspek-aspek mental kejuangan yang ingin dikembangkan adalah: (1) tanggung jawab; (2) disiplin; (3) tangguh dan ulet; (4) kreatif dan adaptif; (5) kemampuan melihat masa depan; (6) kemampuan mengambil keputusan; (7) teguh pendirian; (8) rela berkorban; dan (9) pantang menyerah.

Dari beberapa persepsi siswa yang diwawancarai dapat dimaknai bahwa nilainilai kejuangan Jenderal Soedirman di SMA Taruna Nusantara tidak pernah diberikan secara eksplisit rinciannya. Para siswa sendiri yang harus berpikir dan memaknai apa saja nilai-nilai tersebut. Oleh karena itu, nilai-nilai yang diinternalisasi oleh siswa sangat bergantung kepada wawasan dan kemampuan pamong (guru) dalam menghadirkan nilainilai tersebut melalui pengajaran, pengasuhan, dan pelatihan di satu sisi. Di sisi yang lain bergantung kepada kemampuan siswa dalam memahami, menghayati, dan menginternalisasi nilai-nilai kejuangan tersebut ke dalam diri pribadinya masing-masing.

Nilai-nilai kejuangan Jenderal Soedirman yang dipahami dan dihayati, selanjutnya diinternalisasi oleh siswa dan diaktualisasikan dalam kehidupan sehari-hari. Nilai tersebut menjadi landasan wawasan kejuangan, yang 
menjadi bagian tidak terpisahkan dari wawasan kebangsaan dan wawasan kebudayaan.

Adapun nilai-nilai kejuangan Jenderal Soedirman berdasarkan persepsi beberapa siswa yang diwawancarai, antara lain: (1) pantang menyerah; (2) menjaga kehormatan diri; (3) setia kawan; (4) menjunjung tinggi kebersamaan; (5) nasionalis; (6) patriotis; (7) seorang pendidik; $(8)$ pemimpin perang dan siasat gerilya yang cerdik; (9) pemimpin pasukan yang bersahaja; (10) pemimpin pasukan yang baik, tidak mudah menyerah, memiliki semangat juang yang tinggi, dan tidak menunjukkan lelah di depan pasukan; (11) senantiasa dekat dengan Yang Maha Kuasa, tidak gegabah dan penuh pertimbangan dalam mengambil keputusan serta amanah dalam mengemban suatu kedudukan dan kepercayaan banyak orang.

\section{Proses Internalisasi Nilai-nilai Kejuangan Jenderal Soedirman}

Kegiatan internalisasi nilai-nilai kejuangan Jenderal Soedirman merupakan tahapan penanaman atau tahapan pertama dari empat tahapan (tahapan penanaman, penumbuhan, pengembangan, dan pemantapan) pendidikan karakter di SMA Taruna Nusantara. Tahapan penanaman ini dilaksanakan pada masa awal siswa menjalani pendidikan di SMA Taruna Nusantara, yaitu pada tiga bulan pertama di semester 1 kelas X. Tujuannya agar para siswa memiliki Wawasan Kejuangan.

Internalisasi nilai-nilai kejuangan Jenderal Soedirman dalam pendidikan karakter di SMA Taruna Nusantara dilaksanakan melalui tiga pola tindak yaitu Pengajaran, Pengasuhan, dan Pelatihan. Pola tindak Pengajaran seperti tertera pada Gambar 2, dilaksanakan melalui mata pelajaran Kenusantaraan dan Kepemimpinan $(\mathrm{KnKp})$ dan mata pelajaran Bela Negara (BN). Pola tindak Pengasuhan dilakukan dengan sistem among, di mana para pamong di SMA Taruna Nusantara memberi teladan dan menjadi role model, serta menjadi pendorong bagi para siswa dalam mengaktualisasi nilai-nilai kejuangan. Sedangkan pola tindak Pelatihan dilakukan melalui kegiatan terproyek wajib berupa napak tilas Rute Panglima Soedirman (RPS). Napak tilas tersebut juga merupakan puncak serangkaian kegiatan penanaman nilai-nilai kedisiplinan dan kepemimpinan atau disebut Latihan Dasar Kedisiplinan dan Kepemimpinan (LDKK), yang diikuti oleh semua siswa kelas $\mathrm{X}$ sejak awal masuk tahun ajaran baru dan mencapai puncaknya pada bulan Oktober. Melalui penelusuran kembali (napak tilas) rute perjuangan Jenderal Soedirman diharapkan para siswa terinspirasi dan melakukan internalisasi terhadap nilai-nilai kejuangan yang dipahami dan dihayatinya.

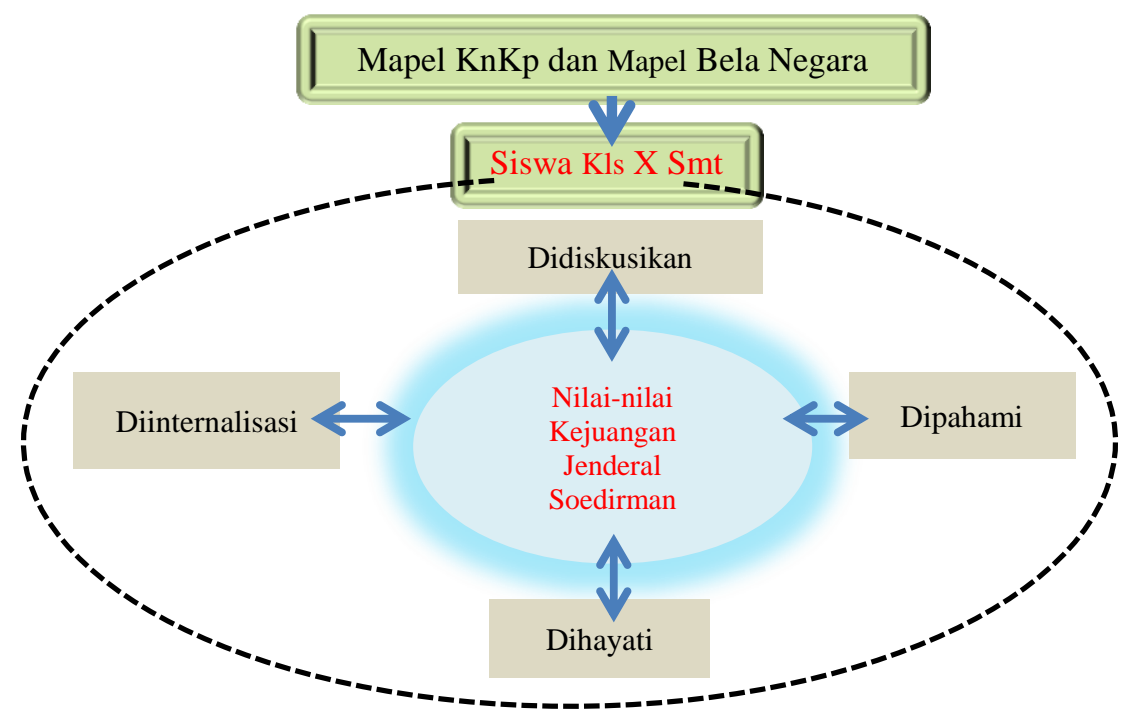

Gambar 2. Internalisasi Nilai-nilai Kejuangan Jenderal Soedirman dalam Pola Tindak Pengajaran di SMA TN

(Sumber: Diolah dari Staf Ahli Bidjamintu SMA TN, 2014) 


\section{Efektivitas Internalisasi Nilai-nilai Kejuangan Jenderal Soedirman}

Berdasarkan pernyataan dari para alumni dapat dimaknai bahwa proses internalisasi nilai-nilai kejua-ngan Jenderal Soedirman telah memberi pengaruh secara efektif terhadap kehidupan siswa atau terhadap pembentukan karakter dan kepribadian siswa. Inilai-nilai kejua-ngan Jenderal Soedirman yang diinternalisasi telah membentuk pribadi yang memiliki semangat berjuang dan bekerja keras untuk mendapatkan apa yang ingin dicapai.

Pada saat RPS para siswa harus melewati serangkaian kegiatan yang cukup menguras tenaga untuk selanjutnya mendapatkan baret biru sebagai ciri khas siswa SMA Taruna Nusantara. Mereka dituntut untuk memiliki nilai kejuangan yang tinggi dan tidak boleh cengeng. Mereka harus melawan rasa kantuk, lelah dan malu untuk bisa terus melaju ke tahap akhir dan mendapatkan baret kebanggaan, walaupun akan muncul banyak rasa sakit dan risiko tekanan fisik yang dialami. Mereka malu untuk gagal. Mereka malu untuk sakit. Hal-hal tersebut secara tak sadar terinternalisasi ke dalam jiwa mereka, dan terbawa ke dunia kuliah maupun kerja, yang menyebabkan beberapa dari mereka akan memiliki semangat juang yang tinggi, pantang menyerah, dan terkadang ambisius dalam mencapai target atau tujuan masingmasing. Ketika mereka sedang dalam masa sulit, mereka ingat bahwa pernah melewati hal yang lebih berat, sehingga mereka pun tidak mudah menyerah untuk hal yang belum berhasil dicapai.

Kehidupan selepas SMA atau kehidupan di bangku kuliah, mencari pekerjaan, meniti karier, dan sebagainya, dibutuhkan daya juang yang tinggi dan semangat yang tidak mudah padam. Internalisasi nilai-nilai kejuangan Jenderal Soedirman berpengaruh dalam menanamkan semangat juang dalam setiap langkah yang mereka ambil selanjutnya. Nilai-nilai tersebut telah mendorong mereka menentukan target untuk lulus tepat waktu dan pencapaian-pencapaian (milestones) dan prestasi tertentu dalam hidup para alumni.

Keteladanan Jenderal Soedirman banyak mempengaruhi proses pembentukan jati diri siswa SMA Taruna Nusantara, terutama kepribadian pantang menyerah dan tidak lelah berjuang. Hal itu melahirkan daya dorong untuk memberikan karya yang terbaik, bagi masyarakat, bangsa, negara, dan dunia dengan tetap berpijak pada nasionalisme dan patriotisme (cinta tanah air). Nilai-nilai kejuangan Jenderal Soedirman telah mendorong sebagian alumni untuk bekerja mengabdi di dalam negeri, dalam berbagai profesi yang membanggakan seperti menjadi dokter, ahli IT, ilmuwan, teknokrat, dan lain-lain.

Internalisasi nilai-nilai kejua-ngan Jenderal Soedirman dalam pendidikan karakter di SMA Taruna Nusantara telah memberi pengaruh secara efektif terhadap pembentukan karakter dan kepribadian siswa. Beberapa alumni yang dimintai pendapat menyatakan secara positif pengaruh dari nilai-nilai kejuangan Jenderal Soedirman yang mereka internalisasi ketika belajar di SMA Taruna Nusantara. Dalam kehidupan mereka sekarang, nilai-nilai tersebut banyak memberi manfaat terutama ketika harus berjuang untuk meraih apa yang dicita-citakan.

\section{SIMPULAN DAN SARAN}

\section{Simpulan}

Nilai-nilai kejuangan Jenderal Soedirman di SMA Taruna Nusantara belum dirumuskan secara eksplisit atau dibakukan sebagai materi pembelajaran. Di dalam dokumen Kurikulum Khusus SMA Taruna Nusantara terdapat aspek-aspek mental yang mengarah kepada nilai-nilai kejuangan Jenderal Soedirman, yaitu: (1) tanggung jawab; (2) disiplin; (3) tangguh dan ulet; (4) kreatif dan adaptif; (5) kemampuan melihat masa depan; (6) kemampuan mengambil keputusan; (7) teguh pendirian; (8) rela berkorban; dan (9) pantang menyerah.

Nilai-nilai yang diinternalisasi sangat bergantung kepada wawasan dan kemampuan pamong (guru) dalam menghadirkan nilainilai tersebut melalui pengajaran, pengasuhan, dan pelatihan di satu sisi. Di sisi yang lain bergantung kepada kemampuan siswa dalam memahami, menghayati, dan menginternalisasi nilai-nilai kejuangan tersebut ke dalam diri pribadinya masing-masing.

Internalisasi nilai-nilai kejuangan Jenderal Soedirman dalam pendidikan karakter di SMA Taruna Nusantara dilaksanakan pada tahapan pertama pendidikan karakter, yaitu tahapan penanaman, menggunakan pendekatan inspiratif dan pola tindak pengajaran, penga- 
suhan, dan pelatihan. Disusun sebagai mata kegiatan terproyek yang wajib diikuti oleh siswa kelas X pada semester 1. Penggunaan pendekatan inspiratif dalam kegiatan internalisasi nilai-nilai kejuangan Jenderal Soedirman membuka peluang para siswa menemukan dan menghayati nilai-nilai lain ketika mereka bersinggungan langsung dengan artefak, diorama fragmen kehidupan, dan fakta-fakta tentang kisah kehidupan dan perjuangan Jenderal Soedirman.

Internalisasi nilai-nilai kejuangan Jenderal Soedirman di SMA Taruna Nusantara berjalan efektif. Proses internalisasi nilai-nilai kejuangan Jenderal Soedirman dalam pendidikan karakter di SMA Taruna Nusantara melalui pola tindak pengajaran, pelatihan, dan pengasuhan telah secara efektif memberikan pengetahuan moral (moral knowing) tentang nilai-nilai kejuangan kepada para siswa. Nilainilai tersebut selanjutnya diinternalisasi oleh siswa sehingga mereka memiliki perasaan maural (moral feeling). Dalam menghadapi permasalahan hidup tertentu, mereka mengaktualisasikan nilai-nilai kejuangan Jenderal Soedirman, atau menjadikan nilai-nilai tersebut sebagai perilaku moral (moral action).

\section{Saran}

Nilai-nilai kejuangan Jenderal Soedirman dalam pendidikan karakter di SMA Taruna Nusantara perlu dirumuskan secara eksplisit dan disusun menjadi materi pembelajaran, sehingga bisa menjadi pedoman para pamong (guru) dalam proses internalisasi nilai-nilai tersebut.

Nilai-nilai kejuangan Jenderal Soedirman adalah nilai-nilai yang bersifat universal dan sesuai dengan nilai kebudayaan Indonesia, sehingga dapat diinternalisasi kepada setiap siswa di Indonesia agar mereka memiliki karakter dan kepribadian yang sesuai dengan kepribadian bangsa Indonesia.

\section{DAFTAR PUSTAKA}

Creswell, J. W. (2007). Qualitative inquiry \& research design: choosing among five approaches. Lincoln: University of Nebraska.

Lickona, T. (1991). Educating for character: how our schools can teach respect and responsibility. New York, NY: Bantam.
LPTTN. (1989). Ketentuan-ketentuan pokok tentang Perguruan Taman Taruna Nusantara. Jakarta: LPPTN.

Madjid, N. (2001). Pembinaan nilai-nilai kejuangan sesuai dengan jati diri bangsa guna menyukseskan PJP-II. In Seminar Nasional. Retrieved from http://www.oocities.org/fauzy70/para/p0 32.html

Miles, M. B., \& Huberman, A. M. (1992). Analisis data kualitatif: buku sumber tentang metode-metode baru. Jakarta: UI Press.

Muhaimin. (1996). Strategi belajar mengajar. Surabaya: Karya Abditama.

Purwoko, D. (2001). Nilai kejuangan dan mekanisme pembudayaannya. In seminar yang diadakan oleh Direktorat Bina Kepahlawanan, Keprintisan, dan Kejuangan Departemen Kesehatan dan Kesejahteraan Sosial di Cisarua. Bogor.

Pusat Bahasa Depdiknas. (2002). Kamus besar Bahasa Indonesia (3rd ed.). Jakarta: Balai Pustaka.

Sastrapratedja, S. J. M. (1993). Pendidikan nilai. In E. K. Kaswardi (Ed.), Pendidikan nilai memasuki tahun 2000. Jakarta: PT. Grasindo.

Scerenko, L. C. (1997). Values and character education implementation guide. Georgia: Georgia Department of Education.

Suhady, I., \& Sinaga, A. M. (2006). Wawasan kebangsaan dalam kerangka NKRI. Jakarta: Lembaga Administrasi NegaraRI.

Walls, K. C., \& Poulton, J. L. (2001). Internalization: The origins and construction of internal reality. Philadelphia: Open University Press.

Wibowo, A. (2012). Pendidikan karakter: Strategi membangun karakter bangsa yang berperadaban. Yogyakarta: Pustaka Pelajar.

YKPP-LPTTN. (2013). Buku kurikulum khusus SMA Taruna Nusantara. Jakarta: LPTTN.

Zubaedi. (2011). Desain pendidikan karakter konsepsi dan aplikasinya dalam lembaga pendidikan. Jakarta: Kencana Prenada Media Grup. 